\title{
Recent ice-core climate records from the Cordillera Blanca, Peru
}

\author{
M. E. Davis, L. G. Thompson, E. Mosley-Thompson, P. N. Lin, \\ Byrd Polar Research Center, The Ohio State University, Columbus, OH 43210, U.S.A. \\ V. N. MikhaLenko, \\ Institute of Geography, Russian Academy of Sciences, Staromonetny 29, Moscow 109017, Russia \\ J. DAI \\ Byrd Polar Research Center, The Ohio Stale University, Columbus, OH 43210, U.S.A.
}

\begin{abstract}
Ice cores recently drilled to bedrock on the col of Huascarán $\left(9^{\circ} 06^{\prime} \mathrm{S}, 77^{\circ} 36^{\prime} \mathrm{W}, 6047 \mathrm{~m}\right.$ a.s.l. $)$ offer the potential for a long, annually resolved climate record from tropical South America. This paper presents the record from 1950 to 1993 preserved in microparticle and nitrate concentrations and oxygen-isotopic ratios. Average monthly temperatures from a satellite-linked automatic weather station installed on nearby Hualcán in 1991 are presented. Annual temperatures from local high-altitude meteorological stations, along with the annual Huascarán isotopic record, show a warming trend over the last two decades. The marked preservation of the climate record in oxygen-isotopic ratios on Huascarán is absent at lower-elevation sites, which have been affected by the recent warming. This paper demonstrates the establishment of a time-scale for the Huascarán core, the preservation of the climatic signal with depth and the linkage of the ice-core "proxy-climate" parameters with measured climatic variations.
\end{abstract}

\section{INTRODUCTION}

Addressing the significance of recent global climatic variations requires a long-term global-scale frame of reference against which present and future changes may be assessed. Fortunately, proxy records for paleoclimatic reconstruction are available from select high-elevation tropical and subtropical ice caps. These records are of particular interest as they are located where climate has a significant impact on human activity. In 1983, two cores were drilled to bedrock on the Quelccaya ice cap $\left(13^{\circ} 56^{\prime} \mathrm{S}, 70^{\circ} 50^{\prime} \mathrm{W}, 5670 \mathrm{~m}\right.$ a.s.l. $)$, located on the easternmost rise of the Andes in southern Peru (Fig. 1). These cores provided much valuable information about climatic variations over the last 1500 years in this region (Thompson and others, 1985, 1986); however, they represent the conditions at a single location. Thus, to distinguish large-scale regional or global phenomena from local events it is necessary to retrieve paleoclimatic histories from other tropical locations. In 1993 two cores were recovered to bedrock from the col of Huascarán $\left(9^{\circ} 06^{\prime} \mathrm{S}, 77^{\circ} 36^{\prime} \mathrm{W}, 6047 \mathrm{~m}\right.$ a.s.l. $)$ in north-central Peru. When complete, the analyses of these cores are expected to provide a climatic history exceeding that from Quelccaya. This paper presents the microparticle (MPC) and nitrate $\left(\mathrm{NO}_{3}^{-}\right)$concentrations and oxygenisotopic ratios $\left(\delta^{18} \mathrm{O}\right)$ for the most recent part of the

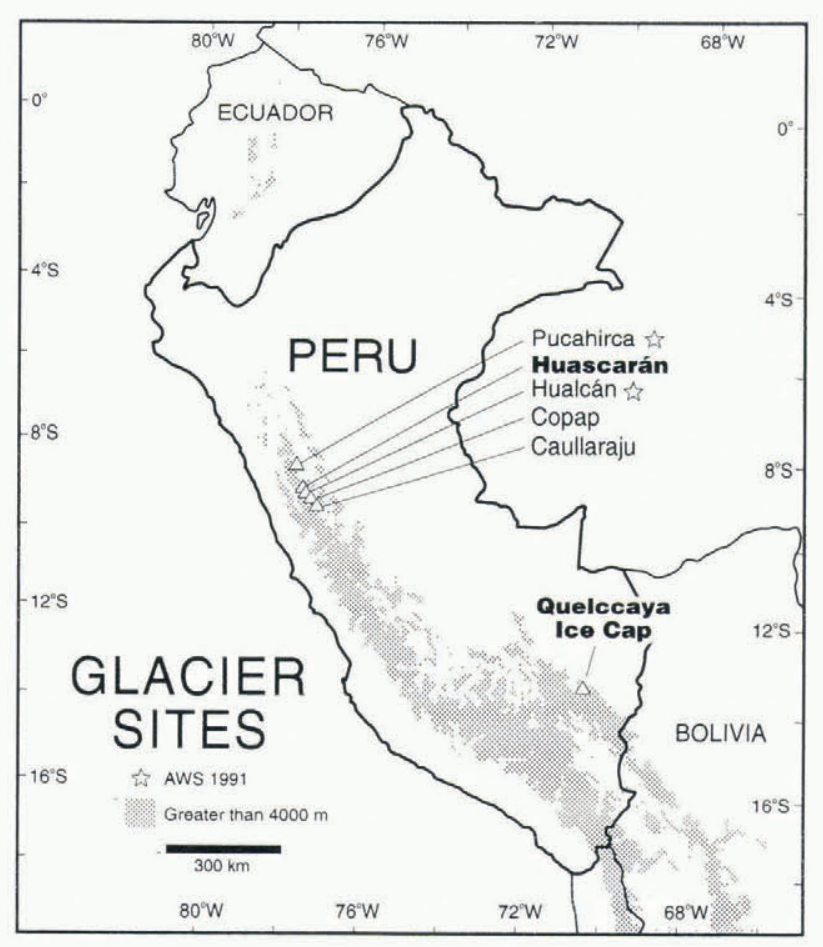

Fig. 1. Map of Peru showing the locations of ice caps in the Cordillera Blanca, the Quelccaya ice cap to the south and the meteorological stations at Recuay and Chiquian. 
record (1950-93), extracted from the upper $57 \mathrm{~m}$ of the Huascarán core.

\section{FIELD AND LABORATORY METHODS}

The drilling was accomplished in July-August 1993 using a portable, lightweight, solar-powered system assembled at the Byrd Polar Research Center. It is designed to be broken into components which can be backpacked into remote sites. The first core, $160.3 \mathrm{~m}$ long, was cut into samples which were melted and bottled in the field. Core 2, $166.1 \mathrm{~m}$ long, was returned frozen to The Ohio State University. The upper $33.5 \mathrm{~m}$ of core 2, which consisted primarily of firn, was cut from the center of the core into separate samples of equal size for each of the analyses. To handle the firn during cutting, several sets of latex gloves were used which had been previously scrubbed in Milli-Q ultra-pure water. Below the firn/ice transition, samples were also cut from the center of the core, but those for MPC and $\mathrm{NO}_{3}^{-}$analyses were transported to a class-100 clean room and washed with Milli-Q water prior to melting.

Concentrations of microparticles with diameters between 2.0 and $40.3 \mu \mathrm{m}$ were measured with a Coulter Counter Model TAII equipped with a $100 \mu \mathrm{m}$ aperture tube. Nitrate concentrations were analyzed using a Dionex Model 2010i ion chromatograph, and $\delta^{18} \mathrm{O}$ was measured using a Finnigan Mat Delta E mass spectrometer.

\section{RESULTS AND DISGUSSION}

At high elevations in the Peruvian Andes, $80-90 \%$ of the annual precipitation occurs as snowfall during the austral summer and fall (November-May). On the col of Huascarán an accumulation/strain network of 15 stakes covering an area of $1.2 \mathrm{~km} \times 2.3 \mathrm{~km}$ was established in September 1991. The stake heights were remeasured and extended in October 1992 and again in July 1993. The 2 year average of annual accumulation $\left(A_{\mathrm{n}}\right)$ is $3.3 \mathrm{~m}$ of snow, or $1.29 \mathrm{mw}$.e.. This is consistent with the results from a $3 \mathrm{~m}$ snow pit excavated in July 1993 adjacent to the drill site which contains 1 year of accumulation. The winter dry season is characterized by higher MPC and $\mathrm{NO}_{3}{ }^{-}$concentrations, and generally less negative $\delta^{18} \mathrm{O}$ (Fig. 2a-c). MPC is also higher during the dry season on the Quelccaya ice cap (Thompson and others, 1979). Concentrations of $\mathrm{Cl}^{-}$and $\mathrm{SO}_{4}{ }^{2-}$ do not display distinct wet/dry season signals.

On Huascarán, as on Quelccaya, the increased MPC and $\mathrm{NO}_{3}{ }^{-}$in the dry season result from high radiation receipt coupled with little snow accumulation (Thompson and others, 1984). Multiple thin radiation crusts are generally associated with the dust peaks. MPC also reflects the nature of and distance from source areas and wind speed. The satellite-linked automatic weather station (AWS) situated on the nearby Hualcán ice cap ( $9^{\circ} 15^{\prime} \mathrm{S}, 77^{\circ} 30^{\prime} \mathrm{W}, 5273 \mathrm{ma}$ a.s.l. $)$ has so far provided temperature and wind data from November 1991 to September 1993. Winds vary from strong northeasterlies during the winter (up to $6 \mathrm{~ms}^{-1}$ in July) to weaker southeasterlies in summer $\left(2.5-4 \mathrm{~m} \mathrm{~s}^{-1}\right)$. Throughout the year, the dominant wind direction is from the Amazon
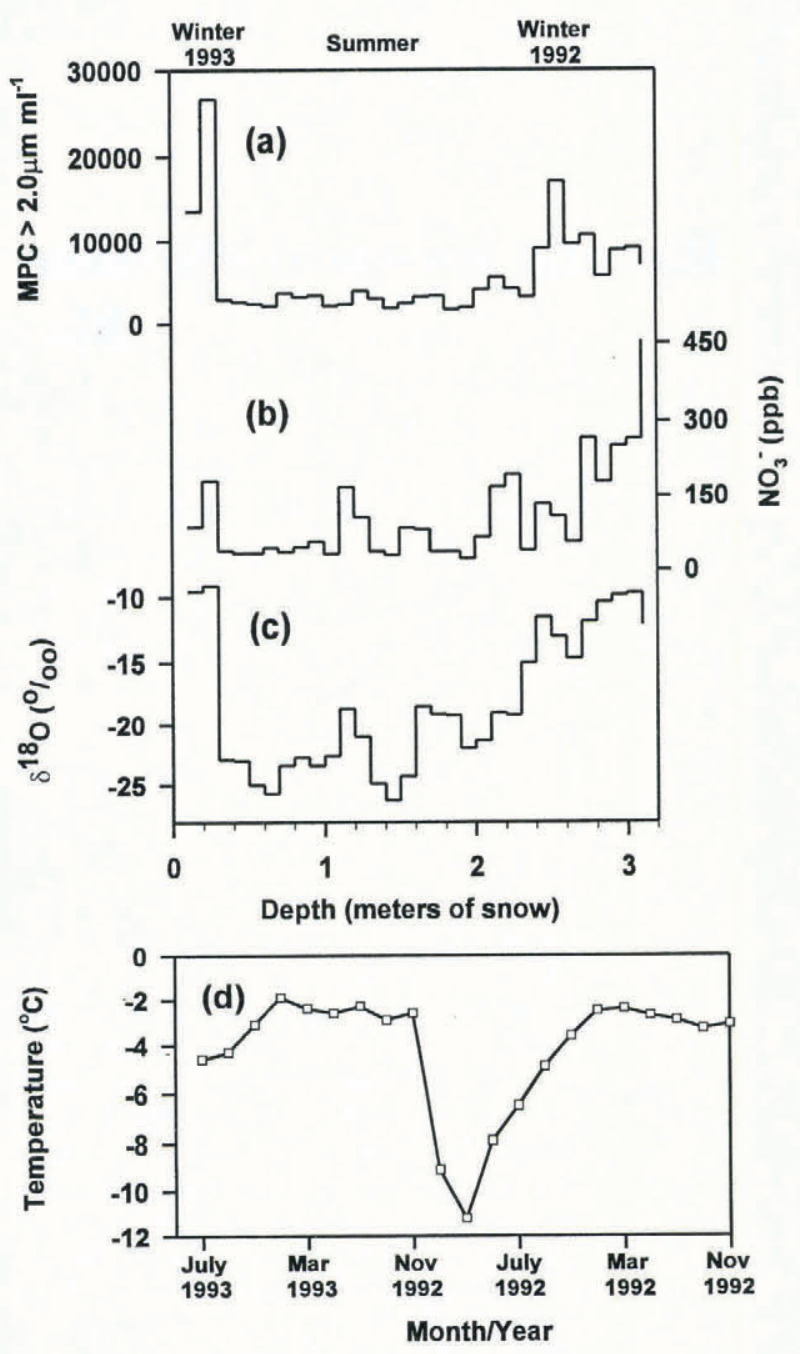

Fig. 2. (a) Microparticle concentrations (MPC), (b) nitrate concentrations $\left(\mathrm{NO}_{3}{ }^{-}\right)$, and (c) oxygen-isotopic ratios $\left(\delta^{18} \mathrm{O}\right)$ for a $3 \mathrm{~m}$ pit excavated in Fuly 1993 adjacent to the drilling site on Huascarain. The pit record represents 1 year of accumulation. (d) Monthly averages of air temperatures from the AWS on neighboring Hualcán, November 1991-July 1993. The winter dry season (May-October) is marked by high $\mathrm{MPC}$ and $\mathrm{NO}_{3}{ }^{-}$ and enriched $\delta^{18} \mathrm{O}$ and lower air temperatures.

basin, a possible source area for much of the dust. This local wind regime is different from that on Quelccaya to the south, where westerlies and northwesterlies dominate in the dry season (Mosley-Thompson, 1982). The observed wind directions at both Huascarán and Quelccaya agree with the large-scale 500 mbar flow pattern described by Chu and Hastenrath (1982).

The ice-core time-scale is based on the seasonal fluctuations in $\mathrm{MPC}, \mathrm{NO}_{3}{ }^{-}$and $\delta^{18} \mathrm{O}$ and is shown (Fig. 3) for three sections in the upper $57 \mathrm{~m}$ of core 2. The thinning of the annual layers with depth is obvious. The annual cycles are depicted as thermal years (i.e. from dry season to dry season) which are easily identified, particularly in $\mathrm{NO}_{3}{ }^{-}$concentrations. This is expected to provide the template for dating the deep core to the depth at which annual resolution is lost due to layer thinning.

Most of the snow on Huascarán which falls in the Southern Hemispheric summer is characterized by ${ }^{18} \mathrm{O}$ depletion (Fig. 2c), which is opposite to the temperature- 

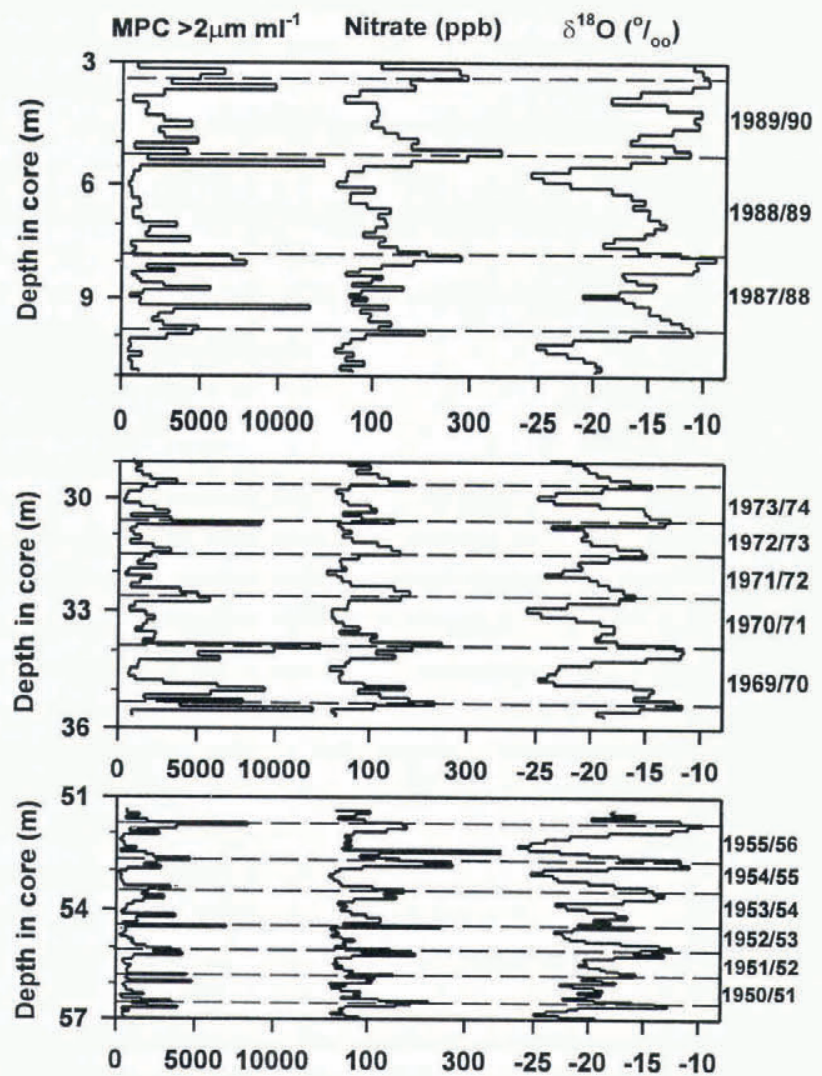

Fig. 3. Three intervals from the Huascarán ice core (1950) 51 to $1955 / 56 ; 1969 / 70$ to $1973 / 74 ; 1987 / 88$ to 1989/90). Time lines (dashed) are drawn to depict thermal years (dry season to dry season). The distinct seasonality in $M P C$ and $\mathrm{NO}_{3}$ is illustrated, as is the thinning of the annual layers with depth.

$\delta^{18} \mathrm{O}$ relationship observed in the polar regions (Dansgaard, 1964). AWS temperature data from Hualcán indicate that the warmest temperatures occur in the summer (Fig. 2d), and the lowest from August to October, at which time snowfall is enriched in ${ }^{18} \mathrm{O}$. The transfer functions essential for interpreting $\delta^{18} \mathrm{O}$ in tropical ice caps are not fully understood. Grootes and others (1989) analyzed the $\delta^{18} \mathrm{O}$ record from Quelccaya and theorized that on a seasonal basis $\delta^{18} \mathrm{O}$ does not strongly reflect temperature as in high latitudes, but results from a combination of factors including air-mass stability and air circulation. Seasonal differences in the isotopic composition of the moisture from the Amazon basin may also be responsible for the isotopic variations in the ice. A more detailed discussion is provided by Molión (1975), Lettau and others (1979) and Salati and others (1979).

Several studies have noted a seasonal and annual "amount effect", which is a relationship between high stable-isotopic ratios and low amounts of precipitation, especially in tropical regions (Dansgaard, 1964; Yurtserver and Gat, 1981; Jouzel and others, 1987). Although on Huascarán and Quelccaya the wet-season snow is isotopically depleted, annually averaged $\delta^{18} \mathrm{O}\left(\delta^{18} \mathrm{O}_{\text {an }}\right)$ and $A_{\mathrm{n}}$ (reconstructed from layer thicknesses) are poorly correlated; the coefficient of determination $\left(R^{2}\right)$ is less than 0.1. For a longer time perspective, Thompson and others (1986) noted that the Little Ice Age on Quelccaya was characterized by depletion in $\delta^{18} \mathrm{O}$ from $\mathrm{AD} 1500$ to
1900 , but that accumulation was above average from 1500 to 1700 and below average from 1700 to 1900. The "amount effect" in the tropics was documented using data mainly from warm $\left(>15^{\circ} \mathrm{C}\right)$, low-elevation sites. It is possible that this relationship does not apply to colder, higher elevations, although more investigation is needed to verify this.

It is of interest to note that while the seasonal temperature range determined from an AWS on Quelccaya is about $2{ }^{\circ} \mathrm{C}$ (Mosley-Thompson, 1982), the AWS data from Hualcán show a $9^{\circ} \mathrm{C}$ difference between winter and summer temperatures (Fig. 2d). The 1993 Huascarán core and the combined records from the two Quelccaya cores show well-preserved seasonality in $\delta^{18} \mathrm{O}$, with a seasonal variation of $\approx 8 \%$ at the surface. However, the seasonal range in Quelccaya decreases to approximately $4 \%$ at $40 \mathrm{~m}$ (Thompson, 1992), which is dated 1950, while that on Huascaran does not decrease with depth in the upper $57 \mathrm{~m}$.

The $\delta^{18} \mathrm{O}_{\text {an }}$ values from the Huascarán core are similar to those found in the Quelccaya ice cap (Thompson and Mosley-Thompson, 1992) for the period 1950-83 (Fig. 4). Not only the trends but also the ranges of the annual averages over the last four decades are comparable at both sites, indicating that they may be affected by the same processes. For example, they share a common wet/dry season moisture source, the Amazon basin and ultimately the Atlantic Ocean (Taljaard, 1972). Similarly, both sites are affected by the same annual cycle of large-scale circulation Chu and Hastenrath, 1982; Thompson and others, 1984). Quelccaya at $5670 \mathrm{~m}$ a.s.l. has an average $\delta^{18} \mathrm{O}$ of $-17.6 \%$ from 1950 to 1983, which is very close to that from Huascarán at 6050 ma.s.l. (-17.3\% from 1950 to 1993. Dansgaard (1964), Ambach and others (1968) and Burk and Stuiver

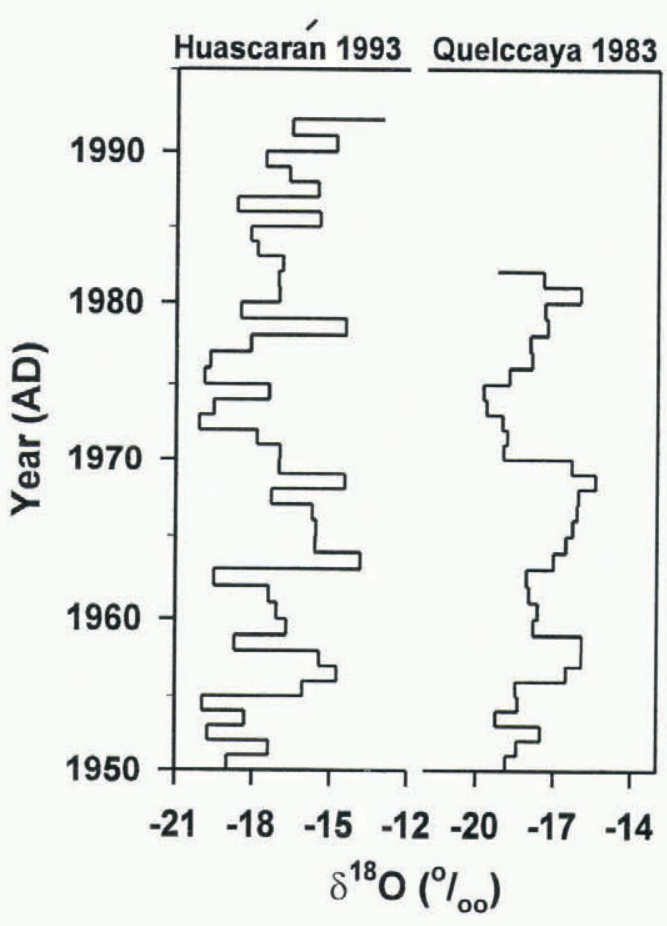

Fig. 4. Annually averaged $\delta^{18} \mathrm{O}$ (1950-92) from the Huascarain ice core, compared with annually averaged $\delta^{18} \mathrm{O}$ from the Quelccaya ice cap (1950 83). 
(1981) suggest that altitude effects are important at lower latitudes, and they indicate an average ${ }^{18} \mathrm{O}$ depletion of $0.2 \%$ per $100 \mathrm{~m}$ of elevation increase. However, Quelccaya is located $4.5^{\circ}$ south of Huascarán, and generally $\delta^{18} \mathrm{O}$ becomes more negative with increasing distance from the equator (Thompson and others, 1984).

How $\delta^{18} \mathrm{O}$ in tropical ice caps is affected by meteorological processes is a relatively new area of investigation. A close relationship between long-term changes in stableisotopic ratios and surface air temperatures has been established for mid- and high-latitude regions Rozanski and others, 1991). The establishment of the AWS on Hualcán and the ongoing collection of pit and surface snow samples will help to establish transfer functions for this tropical location when enough data are collected. Air-mass circulation and the nature and source of precipitation undoubtedly affect $\delta^{18} \mathrm{O}$ in the ice fields in the Andes; however, the evidence discussed below establishes a linkage with temperature.

\section{Recent warming}

Figure 5 compares the $\delta^{18} \mathrm{O}_{\text {an }}$ from Huascarán with annually averaged temperatures from two meteorological stations in the region: Recuay $\left(09^{\circ} 43^{\prime} \mathrm{S}, 77^{\circ} 27^{\prime} \mathrm{W}, 3394 \mathrm{~m}\right.$ a.s.l.) and Chiquian $\left(10^{\circ} 09^{\prime} \mathrm{S}, 77^{\circ} 09^{\prime} \mathrm{W}, 3350 \mathrm{~m}\right.$ a.s.l. $)$. Although the stations are located approximately $2500 \mathrm{~m}$ below the col drill site, all three records contain similar general trends since 1965, the first complete year in which temperature was recorded. Regression analyses yield the following $R^{2}$ values: Recuay and Chiquian, 0.70; Chiquian and Huascarán, 0.40; Recuay and Huascarán, 0.04. The very low $R^{2}$ between Recuay and Huascarán is surprising, given that their profiles appear qualitatively very similar. This may be due in part to the large ranges in seasonal isotopic values and seasonal temperatures on Huascarán (at least $9^{\circ} \mathrm{C}$ ), which are much greater than the ranges of seasonal temperatures from Recuay and Chiquian (2-

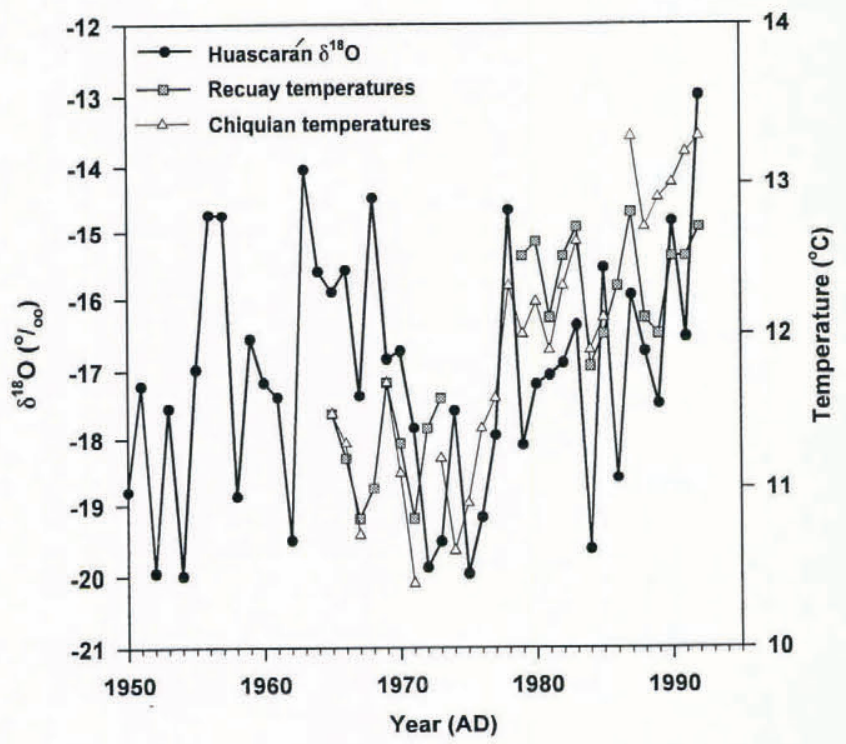

Fig. 5. Annual averages of $\delta^{18} O$ from Huascarán, compared with annually averaged temperatures from two high-altitude meteorological stations in the region. All the records display increasing trends since 1975.
$3{ }^{\circ} \mathrm{C}$. These large intra-annual differences may contribute to an exaggerated range of annual averages of isotopic values seen in Figure 5, compared with the smaller range in temperatures at the meteorological stations. As with the seasonal variations in $\delta^{18} \mathrm{O}$ and temperature, the $\delta^{18} \mathrm{O}_{\text {an }}-$ temperature relationship can be more firmly established when sufficient data have been collected from the Hualcán AWS which, unlike the meteorological stations, is at an elevation comparable to Huascarán.

Of particular interest is the increasing temperature trend beginning in the early 1970s which is contemporaneous with ${ }^{18} \mathrm{O}$ enrichment in the ice core. This recent warming has adversely affected other ice caps in the Cordillera Blanca. The location of an appropriate deepdrilling site was the goal of the 1990 and 1991 field seasons, when reconnaissance expeditions were conducted to several sites: Huascarán, Hualcán, Copap, Pucahirca and Caullaraju (Fig. 1). Shallow cores were collected and analyzed for MPC, $\mathrm{NO}_{3}{ }^{-}$and $\delta^{18} \mathrm{O} . \delta^{18} \mathrm{O}$ was most valuable for evaluating the potential quality of the proxy climate record at each site (Fig. 6). Only the $\delta^{18} \mathrm{O}$ profile from the Huascarán shallow core drilled in 1991 contains distinct seasonality which does not smooth with depth. $\delta^{18} \mathrm{O}$ profiles from the lower-elevation sites display both diminished seasonal ranges and loss of seasonality below a few meters. This isotopic alteration has occurred recently and over a short period of time. For example, the $\delta^{18} \mathrm{O}$ profile from Pucahirca displays large isotopic enrichment and signal smoothing between 1984, when an $8 \mathrm{~m}$ core was retrieved, and 1990 (Fig. 7). The enrichment which occurred during these 6 years was about $3.5 \%$, and the seasonal range decreased from $18 \%$ to $4.5 \%$. Also, during shallow drilling at these lower-elevation sites, layers of percolated meltwater were observed below the surface. This did not occur on Huascarán, where surface melting and

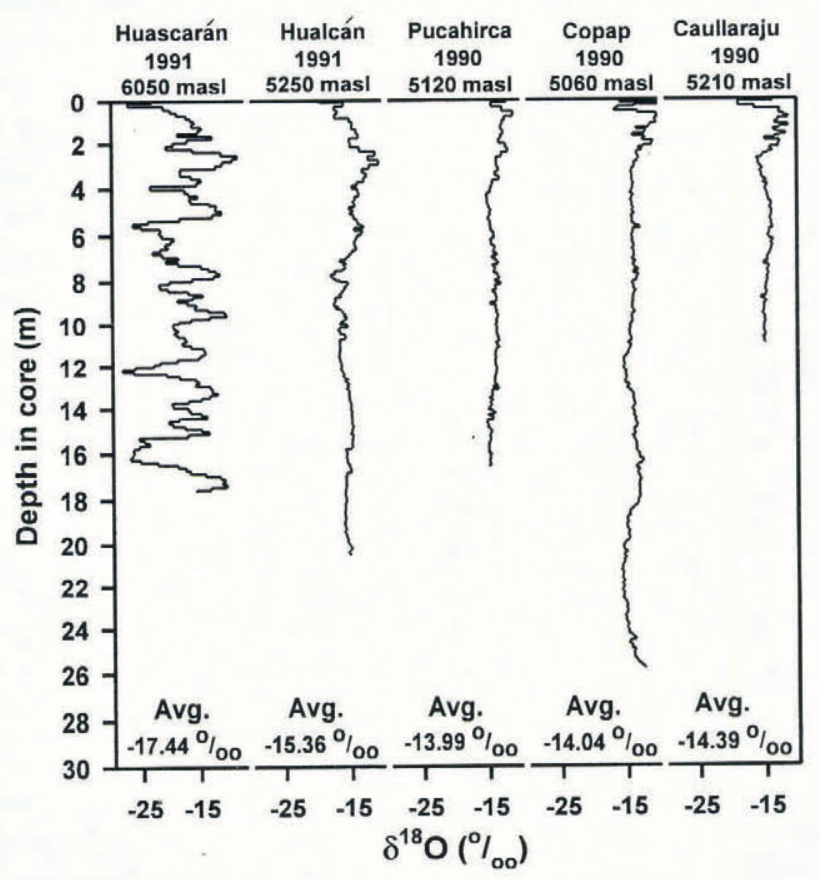

Fig. 6. $\delta^{18} \mathrm{O}$ profiles from lower-elevation sites in the Cordillera Blanca show the smoothing and enrichment of the seasonal signal with depth, and are compared with the well preserved record in Huascarán. 


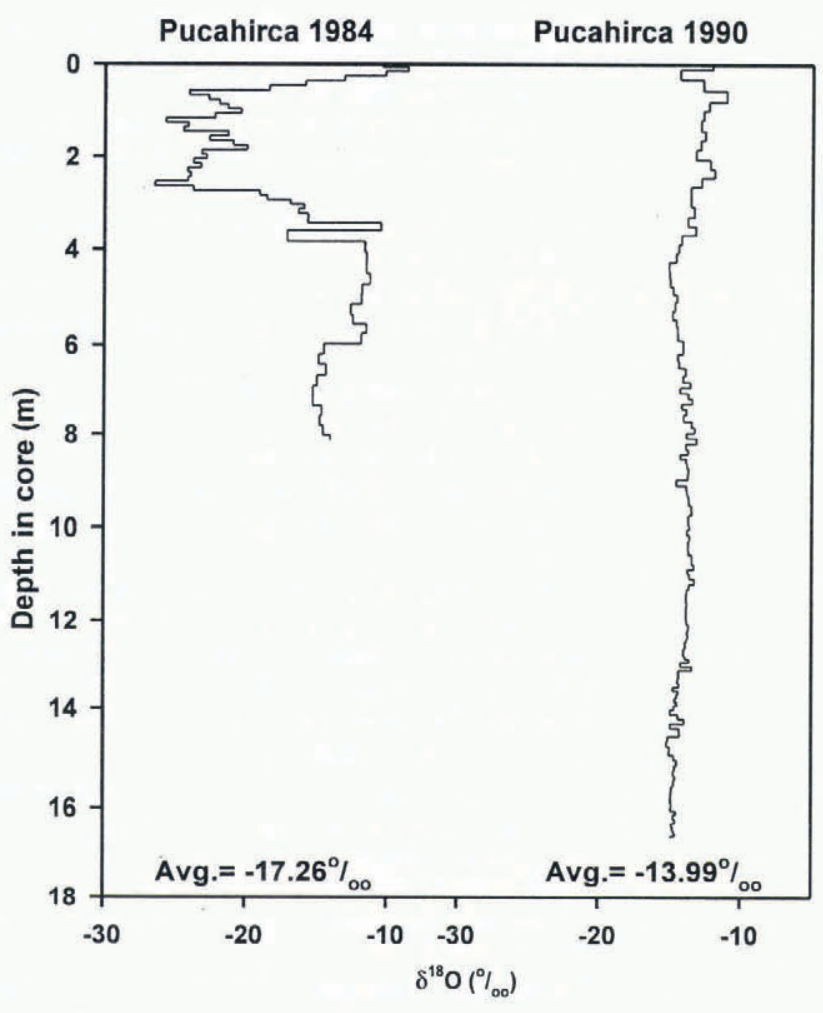

Fig. 7. $\delta^{18} \mathrm{O}$ records from shallow cores recovered from the Pucahirca ice cap in 1984 and 1990 demonstrate the significant isotopic enrichment and smoothing of the seasonal signal over the intervening 6 year interval.

meltwater percolation through the firn were never observed. In fact, these observations were critical for the selection of Huascarán, the highest of these mountains, as the best site for obtaining a preserved proxy climatic record.

This recent warming is occurring not only in northern regions of the Andes but in the southern Andes as well. During a return trip to the Quelccaya ice cap in 1991, the margins, including the Qori Kalis outlet glacier, were found to have drastically receded Brecher and Thompson, 1993). The $\delta^{18} \mathrm{O}$ profile from a shallow core drilled at the summit of Quelccaya in 1991 was noticeably smoothed in comparison with the profile retrieved from the summit in 1976 (Thompson and others, 1993). These data indicate that the elevation of the zone of melting and subsequent water percolation have risen in this area. Recent warming, marked by increases in annual temperatures measured at Recuay and Chiquian, the contemporaneous oxygen-isotopic enrichment in Huascarán and the disappearance of the climate records in the lower-elevation ice caps in the Cordillera Blanca, is also reflected in the Quelccaya ice cap to the south.

\section{CONGLUSIONS}

The new cores from Huascarán contain the bestpreserved seasonality in $\mathrm{MPC}, \mathrm{NO}_{3}{ }^{-}$and $\delta^{18} \mathrm{O}$ yet seen from the Peruvian Andes. Temperature, wind speed and wind direction recorded by the satellite-linked AWS established in 1991 on neighboring Hualcán also vary seasonally. High MPC and $\mathrm{NO}_{3}{ }^{-}$occur in the winter when strong northeasterlies prevail at the $500 \mathrm{mbar}$ level. Seasonal variations in these two parameters are instrumental for dating the core.

Oxygen-isotopic ratios vary in a similar manner to those on the Quelccaya ice cap. However, consistent with other Andean ice cores, and opposite to polar cores, ${ }^{18} \mathrm{O}$ is enriched during the winter. This reflects additional factors such as precipitation source and transport and atmospheric-circulation effects. Annually averaged temperatures from two meteorological stations in the region show an increasing trend over the previous two decades contemporaneous with increasing $\delta^{18} \mathrm{O}_{\text {an }}$ values from Huascarán. Although the processes affecting $\delta^{18} \mathrm{O}$ in tropical snowfields are not fully understood, a positive correlation exists on an inter-annual basis between increasing temperature and less negative oxygen-isotopic ratios.

Annually averaged $\delta^{18} \mathrm{O}$ from the Huascarán ice core is very negative, while that from Copap, Pucahirca, Caullaraju and Hualcán, retrieved in 1990 and 1991, is more enriched (less negative). These differences primarily reflect elevation effects. Many of these ice caps exist at or near the thermal limit, and small increases in atmospheric temperatures are expected to elevate the zones of melting and percolation. This is observed on lower-elevation ice caps in the Cordillera Blanca where seasonal $\delta^{18} \mathrm{O}$ signals are smoothed just a few meters below the surface due to percolation of meltwater. Fortunately, the paleo-climate record on Huascarán is intact. It is the highest tropical mountain in the world, and the drill site is located well above the present thermal limit. The paleoclimatic records from ice caps in this region of the world are disappearing rapidly in response to the recent warming. If this warming trend continues, Huascarán may also cease to preserve a climate record.

\section{ACKNOWLEDGEMENTS}

This research was supported by the National Oceanic and Atmospheric Administration (NOAA-NA16RC0525-01 and NOAA-NA-89AA-D-AC197). The research on the Quelccaya ice cap was supported by the National Science Foundation's Office of Climate Dynamics (NSF ATM 82113601A01). We thank the many scientists, engineers and technicians from Electroperu and the numerous people from the Byrd Polar Research Center, Electroperu and Servicio Nacional de Meteorología e Hidrología (SENAMHI) who participated in the field programs in the Cordillera Blanca. We also extend appreciation to Col. L. A. Alvarez of SENAMHI for supplying the meteorological-station data from the Cordillera Blanca. The Department of Atmospheric and Oceanic Sciences at the University of Wisconsin-Madison constructed the satellite-linked automatic weather station on Hualcán and transmitted the data to The Ohio State University. R. Hellstrom and B. Mark verified and synthesized the AWS data. Dr G. Azuma and Dr C. Hammer reviewed the original manuscript and supplied many valuable suggestions. This is contribution No. 930 of the Byrd Polar Research Center. 


\section{REFERENCES}

Ambach, W., W. Dansgaard, H. Eisner and J. Moller. 1968. The altitude effect on the isotopic composition of precipitation and glacier ice in the Alps. Tellus, 20 4), 595-600.

Brecher, H. H. and L. G. Thompson. 1993. Measurement of the retreat of Qori Kalis glacier in the tropical Andes of Peru by terrestrial photogrammetry. Photogramm. Eng. Remote Sensing, 59(6), 10171022.

Burk, R. L. and M. Stuiver. 1981. Oxygen isotope ratios in trees reflect mean annual temperature and humidity. Science, 211, 1417-1419.

Chu, P. S. and S. Hastenrath. 1982. Allas of upper-air circulation over tropical South America. Madison, WI, University of Wisconsin.

Dansgaard, W. 1964. Stable isotopes in precipitation. Tellus, 16 4), $436-468$.

Grootes, P. M., M. Stuiver, L. G. Thompson and E. Mosley-Thompson. 1989. Oxygen isotope changes in tropical ice, Quelccaya, Peru. $\mathcal{J}$. Geophys. Res., 94(DI), 1187-1194.

Jouzel, J., G. L. Russell, R.J. Suozzo, R. D. Koster, J. W. C. White and W.S. Broecker. 1987. Simulations of the $\mathrm{HDO}$ and $\mathrm{H}_{2}{ }^{18} \mathrm{O}$ atmospheric cycles using the NASA GISS General Circulation Model: the seasonal cycle for present-day conditions. 7. Geophys. Res. 92 (D12), 14,739-14,760.

Lettau, H., K. Lettau and L.C.B. Molión. 1979. Amazonia's hydrologic cycle and the role of atmospheric recycling in assessing deforestation effects. Mon. Weather Rev., 107, 227-239.

Molion, L. C. B. 1975. A climatonomic study of the energy and moisture fluxes of the Amazon basin with considerations of deforestation effects. (Ph.D. thesis, University of Wisconsin.)

Mosley-Thompson, E. 1982. Analysis of the Quelccaya ice cap climate record. Progress report. Columbus, OH, Ohio State University. Institute of Polar Studies.
Rozanski, K., L. Araguás-Araguás and R. Gonfiantini. 1991, Relationship between long-term trends of oxygen-18 isotope composition of precipitation and climate. Science, 256, 981985.

Salati, E., A. Dall'Olio, E. Matsui and G. R. Gat. 1979. Recycling of water in the Amazon basin: an isotopic study. Water Resour. Res., 15, $1250-1258$.

Taljaard, J.J. 1972. Synoptic meteorology of the Southern Hemisphere. Meteorol. Monogr., 13(35), 139-213.

Thompson, L.G. 1992. Ice core evidence from Peru and China. In Bradley, R.S. and P. D. Jones, eds. Climate since A.D. 1500. London, Routledge, 517-548.

Thompson, L. G. and E. Mosley-Thompson. 1992. Tropical ice core paleoclimatic records, Quelccaya ice cap, Peru, A.D. 470 to 1984. Byrd Polar Research Center Miscellaneous Publication 321.

Thompson, L. G., S. Hastenrath and B. Morales Arnao. 1979. Climatic ice core records from the tropical Quelccaya ice cap. Science, $203(4386), 1240-1243$.

Thompson, L.G., E. Mosley-Thompson, P.M. Grootes, M. Pourchet and S. Hastenrath. 1984. Tropical glaciers: potential for ice core paleoclimatic reconstructions. f. Geophys. Res., 89 D3), 4638-4646.

Thompson, L.G., E. Mosley-Thompson, J.F. Bolzan and B.R. Koci. 1985. A 1500-year record of tropical precipitation in ice cores from the Quelccaya ice cap, Peru. Science, 229 4717), 971-973.

Thompson, L. G., E. Mosley-Thompson, W. Dansgaard and P.M, Grootes. 1986. The Little Ice Age as recorded in the stratigraphy of the Quelccaya ice cap. Science, 234(4774), 361-364.

Thompson, L. G. and 6 others. 1993. "Recent warming": ice core evidence from tropical ice cores with emphasis on central Asia. Global and Planetary Change, 7 (1-3), 145-156.

Yurtserver, Y. and J. Gat. 1981. Atmospheric waters in stable isotope hydrology, deuterium and oxygen 18 in the water cycle. I.A.E.A. Tech. Rep. Ser., 210, 103-142. 